\title{
Octaviano y el prodigio de Munda
}

\author{
Santiago Montero Herrero \\ Universidad Complutense de Madrid \\ smontero@ghis.ucm.es
}

\section{RESUMEN}

El prodigio de Munda (45 a.C.), la palmera que una vez cortada se regeneraba con mayor vigor superando el retoño en altura al tronco-madre talado y en la que nidifican palomas, es conocido a través de Suetonio y Dión Casio. Se analiza en la presente contribución las diferentes propuestas de interpretación y se propone el significado del árbol como símbolo de continuidad dinástica y el de las palomas como expresión de la descendencia, por parte de los Julio-Claudios, de la diosa Venus.

Palabras clave: Prodigio. Munda. Dinastía julio-claudia. Venus. Palmera. Palomas.

\section{Octavian and the Prodigy of Munda}

\begin{abstract}
Suetonius and Dio Cassius tell the prodigy of Munda (45 BC): the palm that, once cut, regenerated more vigorously so that the sprout grew taller than the trunk and where pigeons nested. This paper examines the different proposals of interpretation and it argues that the tree must be interpreted as a symbol of dynastic continuity and the pigeons as an expression of the offspring of the goddess Venus down to the Julio-Claudian.
\end{abstract}

Key Words: Prodigy. Munda. Julio-Claudian dynasty. Venus. Palm Tree. Doves. 
En los últimos años han visto la luz diversos trabajos que ponen de manifiesto la importancia que jugaron los prodigios en la vida del joven Octaviano y, más tarde, del Principado de Augusto. ${ }^{1}$ En esta línea, trataré de presentar el significado del prodigio de Munda (45 a.C.) del que no creo necesario recordar sus circunstancias militares y políticas, dado que cuentan con valiosos estudios. ${ }^{2}$ Conocemos el célebre episodio por dos historiadores, Suetonio y Dión Casio:

Apud Mundam Divus Iulius, castris locum capiens cum silvam caederet, arborem palmae repertam conservari ut omen victoriae iussit; ex ea continuo enata suboles adeo in paucis diebus adolevit, ut non aequiperaret modo matricem, verum et obtegeret frequentareturque columbarum nidis, quamvis id avium genus duram et asperam frondem maxime vitet. Illo et praecipue ostento motum Caesarem ferunt, ne quem alium sibi succedere quam sororis nepotem vellet.

(Suet., Aug. 94.11)

"El divino Julio, cerca de Munda, dio orden de talar un bosque que había en el lugar por él escogido para levantar el campamento pero, habiendo hallado en él una palmera, dispuso que la conservaran como símbolo de la victoria. En breve brotó de ella un retoño que en pocos días creció con tanta lozanía que no sólo igualó a la palmera madre sino que incluso la cubrió por completo y la frecuentaban muchos palomos que en ella hacían sus nidos, a pesar de que este género de aves evita cuidadosamente el follaje duro y espeso. Este prodigio, fue uno de los factores que más influyó en el ánimo de César en su decisión de no querer como heredero a nadie que no fuera el nieto de su hermana"

(trad. Bassols de Climent).

"Aunque César hubiera preferido morir en Hispania en la gloria de la guerra, enfrentándose a sus enemigos, sin embargo lo hizo en su patria, en el Senado, a manos de sus amigos más queridos, como así sucedió de hecho poco después. Esta guerra [la de César contra los pompeyanos en Munda] fue la última que (César) llevó a feliz término; fue su última victoria. Ciertamente no era una gran empresa de la que no cupiese esperar nuevos acontecimientos: éstos fueron indicados por varias señales, y en modo especial por el vástago que creció al lado de una palmera que se encontraba en el campo de batalla, poco después de la victoria. No hace falta decir que el prodigio tenía un significado, que sí que lo tenía, pero no para él, sino para un descendiente de su hermana, Octavio, el cual estaba en el campamento junto a César y estaba destinado a obtener los beneficios de las fatigas y de los peligros de César. El dictador, sin embargo, ignoraba todo esto; y esperando hacer nuevas y grandes conquistas, no daba muestra alguna de modestia, y se comportaba como si fuera inmortal"

(Dión Casio, Historiae Romanae XLIII 41. Trad. S. Perea).

Aunque ambos relatos presentan algunas diferencias entre sí vemos cómo la palmera que crecía en las inmediaciones de Munda, una vez cortada, se regeneraba con

1 Cf., por ejemplo, Flory 1988; BerTRAND-ECANVIL 1994; Vigourt 2001.

2 Es imprescindible: Melchor Gil - Mellado Rodríguez - Rodríguez Neila 2005; Le Bohec 2010. Sobre el escenario geográfico de la batalla: Blanco Freijeiro 1983; Durán Recio - Ferreiro López 1984. 
mayor vigor superando el retoño en altura al tronco-madre talado. Además, en ella nidificaron palomas pese a la dureza de su follaje.

El prodigio, como ya observan ambos autores, trataba de establecer un vínculo que ligara al joven Octaviano con César, es decir, que marcara la continuidad entre ambas figuras en un intento, como luego veremos, de hacer creer desde las instancias oficiales que César le había elegido ya, mucho antes de la adopción oficial del 13 de septiembre del 45. Pero Octaviano nunca llegó a participar en la batalla; de hecho solo Veleyo (II 59.3: natumque annos XVIII Hispaniensis militiae adsecutum se postea comitem habuit) y Dión Casio (43.41: “Octavio estaba en el campamento junto a César") lo creían así. Nicolas de Damasco, mejor informado, dice que Octaviano llegó a Munda cuando la batalla había terminado. El episodio ha merecido la atención de L. Canfora en su excelente monografía sobre el dictador, subrayando "los oscuros initia" del futuro princeps. Sostiene el erudito italiano que, en realidad, Octavio no estuvo en Munda, que apareció “con retraso" junto a César: llegó siete meses después de la campaña cesariana cuando la guerra ya había acabado. En definitiva sólo permaneció en Hispania durante los meses de junio a agosto del $45 .^{3}$

El "prodigio" pudo proceder de Livio 4 de quien debió de tomarlo Suetonio y quizá Dión. Pero es evidente que Livio no lo inventa: su relato descansó sobre la propaganda del entourage del emperador y ésta, a su vez, sobre algún "hecho" o "núcleo" histórico.

La historiografía antigua (en realidad ya el propio Suetonio y Dión Casio) y moderna rechaza una interpretación del prodigio en favor de César y lo atribuyen a Octaviano. Así, por ejemplo, E. Bertrand-Ecanvil $1^{5}$ quien lo presenta como el que ha determinado la elección por César de su sobrino-nieto. En efecto, el prodigio estaría fundamentalmente destinado a hacer creer que la adopción de Octaviano remonta a marzo del 45, meses antes de que fuese oficial (septiembre) y, sobre todo, que tuvo lugar por mediación divina: la diosa Venus se sirve de elementos animales y vegetales para advertirlo. Es el propio César el que lo interpreta sin la ayuda o mediación de adivinos: ninguno de los textos menciona la intervención de los arúspices, cuya consulta debió ser intencionadamente evitada cuando, sin embargo, eran expertos en este tipo de prodigios. Recuérdese que ya en el año 199 a.C. fueron llamados por el Senado cuando se produjo un prodigio arbóreo, lo que obligó a realizar una supplicatio a modo de expiación. ${ }^{6}$ El arúspice etrusco Tarquitius Priscus escribió un Ostentarium

3 CANFORA 2007. Sobre la presencia de Octaviano en Hispania: CURCHIN 2002.

4 Cf. Syme 1959. CANFora 2007, 74 escribe que "los historiadores "hinchan" las gestas del joven Octavio". Una fecha tardía vendría corroborada por la ausencia de toda mención al prodigio tanto en el Bellum Hispaniense de César como en la biografía de Augusto escrita por Nicolás de Damasco.

5 BerTRAND-ECANVIL 1994.

6 A P. Sulpicio proconsule ex Macedonia litterae adlatae, in quibus inter cetera scriptum erat lauream in puppi nauis longae enatam. Priorum prodigiorum causa senatus censuerat ut consules maioribus hostiis quibus diis uideretur sacrificarent; ob hoc unum prodigium haruspices in senatum uocati, atque ex responso eorum supplicatio populo in diem unum indicta et ad omnia puluinaria res diuinae factae (Liv. 32.1.12). Un listado de los prodigios arbóreos en Roma permitiría llegar a dos conclusiones inmediatas: que se trata de un tipo de prodigio muy excepcional (en relación a los telúricos o a los celestes, por ejemplo) y, sobre todo, que comienzan a registrarse tardíamente. Este es, precisamente, el primero. 
arborarium, ${ }^{7}$ una traducción quizá de uno de los libros de la Etrusca disciplina, medio siglo antes de que los arúspices intervinieran decisivamente en favor de Vespasiano tras el examen de un retoño de encina. ${ }^{8}$

En el prodigio existen dos elementos que conviene examinar. Por una parte las palomas (Suetonio) que son las que dan el signo y no están elegidas al azar. Como he advertido en otros estudios ${ }^{9}$ las palomas (aves consagradas a Venus, madre de Eneas y antepasada de los Iulii) anunciaban la próxima llegada del joven Octaviano al poder, a la monarquía puesto que tradicionalmente dichas aves venían siendo asociadas a la realeza, como nos recuerda Servio:

Columbae non nisi regibus dant auguria quia numquam singulae uolant, sicut rex numquam solus incedit.

(Serv., ad Aen. I 193)

...nam ad reges pertinet columbarum augurium, quia numquam solae sunt, sicut nec reges quidem.

(Serv., ad Aen. VI 198).

Por otra parte, tenemos la palmera, de la que brota milagrosamente un vástago o retoño que acaba superándola en altura. Cabría interpretar a primera vista la palmera como lo que siempre había sido en el mundo helenístico y romano: símbolo -en este caso presagio- de la victoria de César sobre los pompeyanos. No era la primera vez que este elemento vegetal irrumpe en la vida de César: pocos años antes, tras la victoria del dictador en Farsalia, una palmera apareció milagrosamente en el postamento de una estatua dedicada a César en el templo de la Victoria de Trales. ${ }^{10}$ De hecho sue-

7 Macrob., Sat. III 20.3. Thulin 1968, III, 94: "Dass die Bäume eine wichtige Rolle in der etruskische Lehre von den Ostenta spielten, ersehen wir aus den Titel ostentarium arborarium, der einen Teil der von Tarquitius Priscus übersetzen Ritualbücher bezeichnet”. Sobre la obra de Tarquitio Prisco, cf. MonTERo 2005.

8 Según Suetonio (Aug. 5.2.3), cada vez que Vespasia, madre de Vespasiano, daba a luz, crecía una nueva rama en una encina situada en la finca familiar. La primera nació delgada y se secó enseguida, muriendo la hermana de Vespasiano antes de cumplir un año, la segunda, larga y fuerte, vaticinaba para Sabino una vida larga y próspera pero la tercera, similar a otro árbol, simbolizaba el destino reservado para Vespasiano: la dignidad imperial. El prodigio es diferente del que años antes tuvo lugar en un terreno de los abuelos del futuro emperador Vespasiano: un ciprés fue derribado de raíz sin que se produjera ningún tipo de tempestad aunque al día siguiente el árbol volvió a levantarse más verde y firme que nunca. Cf. Suet., Vesp. 5.4: Tac., Hist. II 78; D.C., 66.1.3.

9 Montero 2006; Montero 2014. Obsérvese, además, que los pichones buscan siempre sitios altos: Varrón (RR III 71), Horacio (Carm. I.2.9-10), Plinio (NH X 110).

10 Caes., BC III 105.6: item Trallibus in templo Victoriae, ubi Caesaris statuam consecraverant, palma per eos dies [in tecto] inter coagmenta lapidum ex pavimento exstitisse ostendebatur. Valerio Máximo se hace eco también del prodigio señalando que, junto a otros, podía deducirse "que las celestiales divinidades favorecían la gloria de César": quo constat in delubris deum sua sponte signa conuersa, militarem clamorem strepitumque armorum adeo magnum Antiochiae et Ptolemaide auditum, ut in muros concurreretur, sonum tympanorum Pergami abditis delubri editum, palmam uiridem Trallibus in aede Victoriae sub Caesaris statua inter coagmenta lapidum iustae magnitudinis enatam. quibus apparet caelestium numen et Caesaris gloriae fauisse et Pompei errorem inhibere uoluisse (Mem. 1.6.12.14-23). También se hacen eco del prodigio de Trales: Obs. 65a (Palma viridis Trallibus in aede Victoriae sub Caesaris statua intra coagmenta lapidum magnitudine matura enata); Plin., NH XVIII 244: Simili modo Trallibus palma in basi Caesaris dictatoris circa bella civilia meius); Plut., Caes. 47.18 y Dión Cass. XLI 61.4. Cf. WeInstock 1971, 97; FishwiCK 1982, 226; VigOuRT 2001, 120. 
le olvidarse que en el territorio de Cumas un árbol se desplomó, con funesto presagio, poco antes de las guerras civiles de Pompeyo Magno (Plin., NH XVII 243: Subsedit in cumano arbor gravi ostento paulo ante Pompei Magni bella civilia paucis ramis eminentibus). Los dioses se sirven pues de un doble ostentum arborarium: uno desfavorable para Pompeyo, otro, el de Munda, favorable a César.

Pero aquí se trata de un ostentum arborarium que parece anunciar claramente que el futuro Augusto superará en grandeza a su padre adoptivo. El árbol no es elegido al azar: "La destinée d'un chef puissant, de sa famille, de son genos, de sa dynastie, est de même liée à celle d'un arbre", escribió Deonna. ${ }^{11}$ Después de Munda-según la ficción de la propaganda- Octaviano quedaba místicamente unido, a los ojos de todos, a César a través de la palmera. Años más tarde incluso el destino de su sobrino Marcelo al que él había elegido como sucesor pero que moriría tempranamente es comparado por Horacio al de un árbol: Cressit, occulto velut arbor aevo, fama Marcelli (Od., I.12). Si bien no guarda relación directa con la dinastía de los Julio-Claudios (o quizá precisamente por ello), Galba exhibía un impresionante árbol de familia en el atrio de su casa para mostrar así su descendencia de Júpiter y Pasifae (Suet., Galba 2). Recientemente E. Gowers advierte: "Although the Romans had no family "trees" as such, their genealogical stemmata ("garlands") had "branches" (rami) and "stock" (stirps), and their vocabulary of family relationships takes many of its metaphors from planting, adoption, and uprooting, while plant life is often described in human metaphors". ${ }^{12}$

En este punto es preciso recordar un decisivo artículo de Sabino Perea ${ }^{13}$ quien llamó la atención de un texto olvidado de Plinio, escueto pero que aporta claves interpretativas para el episodio de César en Munda:

Palmati circa Mundam in Hispania, ubi Caesar dictator Pompeium vicit, reperiuntur idque quotiens fregeris

(N.H. XXXVI 134)

"En los alrededores de Munda, en Hispania, donde César nombrado dictador venció a Pompeyo, se encuentran piedras en forma de ramas de palmera, que conservan esa forma por muchas veces que las rompas".

Perea habla de una "racionalización" del prodigio más sensata que la aportan Suetonio y Dión, y, sobre todo, más creíble. En su opinión las "piedras vivas" mencionadas por Plinio son posiblemente rocas de sílice o piritas, "fósiles con forma vegetal o de palmera" y posible núcleo que dio origen a la leyenda del vástago de palmera: "el prodigio del vástago de palmera, perfectamente comprensible para un naturalista como Plinio, fue contado ("literaturizado") por otros en un sentido bien distinto. Para que el evento, verdaderamente anecdótico y sin importancia, fuese tenido como pro-

11 Deonna 1951, 55.

12 Gowers 2011, 87.

13 Perea Yébenes 2005. 
digio bastaba con cambiar los fósiles con forma vegetal o de palmera por una palmera vegetal viva". ${ }^{14}$

En esa misma línea de racionalización, y siguiendo el magnífico estudio de Perea, encontramos la interpretación reciente de un geólogo del CSIC, el prof. Juan Manuel García Ruiz, ${ }^{15}$ quien cree que se trata de rocas de agregados cristalinos con formas palmeriformes, estructuras de cristales curvos de yeso messiniense en forma de palma que pueden encontrarse en distintos lugares de la Cordillera Bética.

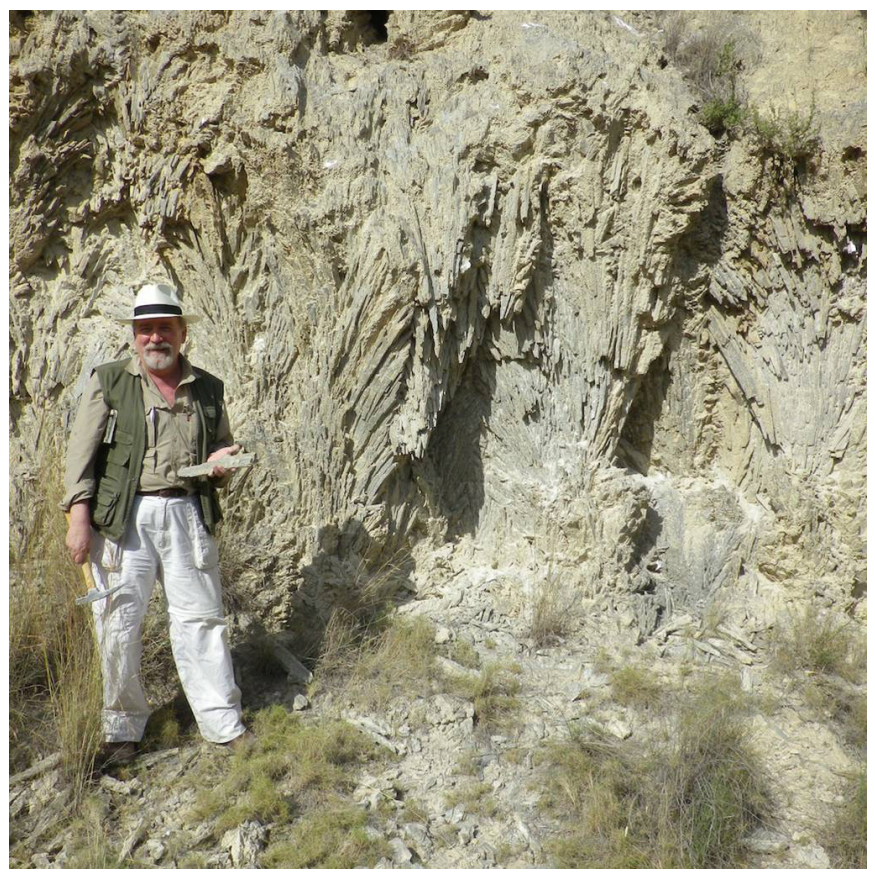

Fig. 1. El profesor Juan Manuel García Ruiz en la Cordillera bética.

El prodigio de Munda debió de dejar su recuerdo en un pasaje de la Eneida de Virgilio: aquel en el que Eneas es guiado por dos palomas hacia el árbol del que brota la rama de oro:

"Apenas había hablado, cuando por caso dos palomas bajaron volando del cielo ante sus ojos y se posaron en el verde suelo. El gran héroe entonces reconoció las aves de su madre y alegre implora:

"Sed mi guía, si es que hay algún camino, y alzad el vuelo por el aire hasta el bosque donde la espléndida rama da sombra al pingüe suelo. Y tú no me falles en mis dudas,

14 Perea Yébenes 2005, 10.

15 García Ruiz 2011, 95. 
madre divina". Dicho esto detuvo sus pasos

estudiando qué señales anuncian, hacia dónde prosiguen.

Ellas vuelan en busca de alimento tanto cuanto abarcar podrían los ojos de quienes las siguieran.

Más tarde, cuando llegaron a las fauces del Averno de pesado olor, se elevan presurosas y dejándose caer por el líquido aire se posan en el lugar ansiado sobre un árbol doble desde donde relució distinta entre las ramas el aura del oro"

(Virg., Aen. VI 190-204, trad. R. Fontán)

No es difícil relacionar las palomas que guían a Eneas hacia la encina significando la protección de Venus Victrix sobre la raza de Eneas con las palomas que intervienen en Munda. El pasaje de Virgilio permite reconocer a las palomas como aves augurales: buscan alimento (columbae... pascentes), lo que parece de buen augurio; el poeta emplea además una gran cantidad de tecnicismos augurales (ipsa sub ora, vestigia pressit, observans, pascentes, quae signa fuerant...). No se trata, pues, de un signo dado fortuitamente por las aves: la descripción virgiliana obedece a las técnicas de la vieja auguratio romana. ${ }^{16}$

El vínculo de Octaviano con las palomas explica la posterior reorganización de los sodales Titii que han sido objeto por mi parte de un estudio específico. ${ }^{17} \mathrm{La}$ característica de esta sodalitas de la que Augusto formó parte (según recuerda en sus Res Gestae) era la observación a través del vuelo y el tripudium de los titii, aves que tres autores antiguos identifican con la paloma selvática:

Titos scholasticos, quod sint vagi neque uno magistro contenti, et in libidinem proni, sicut aves, quibus comparantur, nam titi columbae sunt agrestes.

(Schol. Pers. 1.20)

PaLUMBES columbae, quas vulgus tetas vocat. Et non dicuntur latine, sed multorum auctoritas latinum fecit: Cicero in elegia, quae $<>$ talia masta inscribitur iam mare Tyrrhenum longe penitusque palumbes reliquit.

(Serv., ad ecl. 1.57)

Palumbes [eo quod sint farsae, a pabulo; quas vulgus titos vocant.

(Isid., orig. XII 7-62)

Esta institución pudo ser creada (o reformada) por Augusto en el año 29 (al igual que la sodalitas de los arvales estudiada por Scheid) si bien es preciso recordar que Octaviano era ya augur desde el 41-40 a.C. En la I Bucolica de Virgilio, Titiro, pastor que conserva sus propiedades gracias a Octavio no oculta su interés por las palomas: 10) hinc alta sub rupe canet frondator ad auras; / nec tamen interea raucae, tua cura, palumbes / nec gemere aëria cessabit turtur ab ulmo (Virg., ecl. 1.57). Todo ello

16 Gowers 2011.

17 Montero 2014. 
viene a demostrar el interés de Augusto por la auguratio y su explotación política de la técnica augural.

Es posible que la influencia del prodigio de Munda sobre la obra de Virgilio no sea la única: en Fastos III, 11-40, Ovidio narra cómo de la cinta de lana caída de Rea Silvia nacen dos palmeras, una mayor que otra. Amulio intenta cortarlas pero la loba y el pico-verde las defiende. Y aún tenemos el célebre epigrama IX, 61 de Marcial dedicado al plátano plantado por César en Corduba: ${ }^{18}$

In Tartesiacis domus est notissima terris,
qua dives placidum Corduba Baetin amat,
vellera nativo pallent ubi flava metallo
et linit Hesperium brattea viva pecus.
aedibus in mediis totos amplexa penates
stat platanus densis Caesariana comis,
hospitis invicti posuit quam dextera felix,
coepit et ex illa crescere virga manu.
auctorem dominumque nemus sentire videtur:
sic viret et ramis sidera celsa petit.
saepe sub hac madidi luserunt arbore Fauni
terruit et tacitam fistula sera domum;
dumque fugit solos nocturnum Pana per agros,
saepe sub hac latuit rustica fronde Dryas.
atque oluere lares comissatore Lyaeo
crevit et effuso laetior umbra mero;
hesternisque rubens †delecta† est herba coronis
atque suas potuit dicere nemo rosas.
o dilecta deis, o magni Caesaris arbor,
ne metuas ferrum sacrilegosque focos.
perpetuos sperare licet tibi frondis honores:
non Pompeianae te posuere manus.

Generalmente se acepta que el plátano fue plantado por César tempranamente, durante su presencia en la Ulterior como pretor o cuestor, pero en época domicianea el poeta, no sin cierta ambigüedad, no se resiste a ambientarlo durante la batalla de Munda. Curbera y Galaz creen con razón que el episidio debió de tener lugar antes de la batalla pero reconocen que "el último pentámetro non Pompeianae te posuere manus, nos sitúa en la batalla de Munda" y que el verso 7 (hospitis invicti posuit quam dextera felix) también parece oponerse a la interpretación más extendida. ${ }^{19}$ En cualquier caso, como en el prodigio de Munda, es llamativa la insistencia en la altura del plátano (et ex illa crescere virga manu....; sic viret et ramis sidera celsa petit) así como en la densidad de su follaje (platanus densis Caesariana comis: compárese con genus duram et asperam frondem maxime vitet del texto de Suetonio). En suma, en el prodigio de Munda el árbol es un elemento simbólico de la continuidad dinástica,

18 Curbera - Galaz 1995; Meulder 2006; Marks 2010.

19 Curbera - Galaz 1995, 155. 
mientras las aves simbolizan una vez más a Venus -Genetrix-y los remotos orígenes de la dinastía; ambos son pues complementarios en la propaganda augustea.

Pero la palmera aún irrumpirá de nuevo en la vida de Augusto cuando años más tarde, brote espontáneamente en el altar consagrado al emperador en Tarraco. Que se trataba de un prodigio es algo que está fuera de toda duda pues el propio Plinio dice que prodigios son los árboles que nacen en lugares insólitos, como sobre las cabezas de las estatuas o sobre los altares o cuando sobre los árboles mismos crecen árboles diversos (NH XVII 244: Sunt prodigia et cum alienis locis enascuntur, ut in capitibus statuarum vel aris, et cum in arbororibus ipsis alienae). El prodigio es conocido tanto por un breve texto de Quintiliano ${ }^{20}$ como por un sestercio acuñado en esta colonia en época de Tiberio. ${ }^{21}$ En el anverso, junto a la cabeza radiada de Augusto a la izquierda, se lee: DIVUS AUGUSTUS PATER. En el reverso, un palmito naciendo sobre el focus de un altar; el panel frontal está decorado con el motivo de los bucráneos unidos con guirnaldas y panoplia central de escudo y lanza, acompañado de la leyenda C(olonia) U(rbs) T(riumphalis) T(arraco).
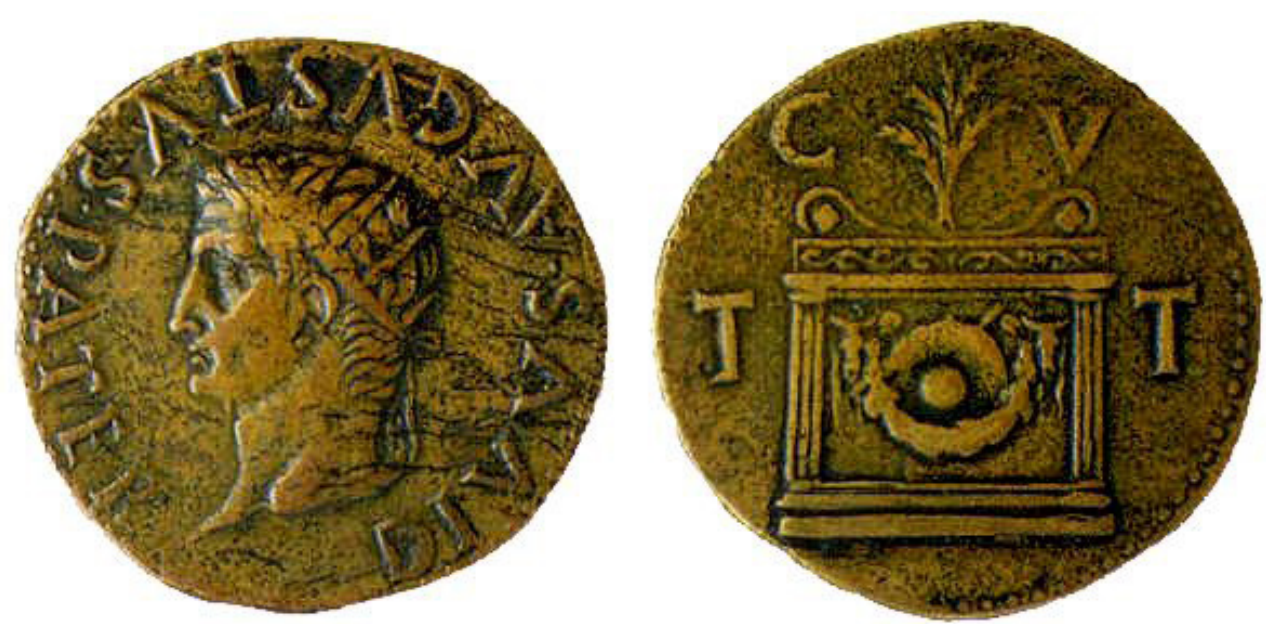

Fig. 2. Sestercio de Tiberio con la cabeza radiada de Augusto en el anverso y un palmito naciendo del focus de un altar en el reverso.

Tanto Étienne como Fishwick atendieron a la iconografía del reverso ${ }^{22}$ pero más recientemente A. Ruiz de Arbulo escribe al respecto: "El palmito (chamerops humi-

20 Quint., Inst. VI 3.77: Et Augustus, nuntiantibus Terraconensibus palmam in ara eius enatam, 'apparet' inquit 'quam saepe accendatis ("los tarraconenses anunciaron a Augusto que una palmera había nacido sobre el altar a él dedicado. "Parece -respondió- que no lo hacéis servir demasiado").

21 RPC 218. Villalonga 1977, 139-157 (cf. Addenda et corrigenda en $\mathrm{n}^{\circ} 7$ [1978], pp. 179-180); RPC I, 218, 221, 225, 231; BurnetT 1992, 104. Para el mundo griego (cerámica ática del siglo V): SourVINOUINWOOD 1985.

22 Cf. los comentarios iconográficos de ÉTIENNE 1958, 369 y Fishwick 1982, 225 quien considera el altar como de culto municipal, probablemente dedicado al culto conjunto de Roma y Augusto e instalado en el foro republicano, en la parte baja de la ciudad. 
lis, margalló en catalán) es una planta propia del entorno mediterráneo tarraconense. El altar ofrendado a Augusto no sería una pieza maciza de mármol, de uso todavía muy poco extendido fuera de Roma, sino una obra formada por un relleno interior revestido por losas de arenisca estucada o placas de caliza. La germinación de una semilla en el relleno interior de tierra y piedras pudo pues provocar el nacimiento de un palmito, una pequeña palmera". ${ }^{23}$ No cree este estudioso que el altar fuera dedicado durante la estancia de Augusto en Tarraco (recordemos que permaneció en la ciudad en dos ocasiones: 26 y 15 a.C.) y considera que "la ofrenda de este altar, que inauguró el culto imperial en las provincias occidentales, es una iniciativa compleja, difícil de entender desde la tradición republicana de los cives pero no desde la perspectiva clientelar y servil romana del culto privado al genius del patrono y, sobre todo, por la directa dependencia de fidelidad personal creada en los medios militares de la República Tardía entre las tropas y su imperator, un proceso acelerado durante la última fase de las guerras civiles". ${ }^{24}$ Por su parte I. Rodá cree que tanto el pasaje de Quintiliano como la amonedación de Tarraco son muy significativos "pues atestigua el funcionamiento de un culto a la figura del emperador ya en vida". ${ }^{25}$

Partiendo del escepticismo al respecto de G. Alföldy, E. Castillo Ramírez considera que de la cita de Quintiliano no puede deducirse la asociación del altar con un "culto a Augusto" ni tampoco de las monedas, que únicamente dan prueba de la importancia que debió de tener el altar como monumento representativo de la colonia ${ }^{26}$. Añade, finalmente, que la característica principal, que hace del altar un motivo único en la numismática romana, es la palma que exhibe sobre su coronamiento: "Esta peculiaridad tiende a asociar de forma casi inmediata la imagen de las monedas con la anécdota de Quintiliano. Sin embargo, la vinculación no tuvo por qué existir. Si atendemos a la asociación entre el monumento y la leyenda que lo acompaña, podríamos pensar que se tratara de un altar conmemorativo de la colonia, sobre el que se instaló una palma de la victoria, elemento simbólico estrechamente ligado a la faceta militar de la política augustea y de la fundación de la colonia a partir de una deductio de veteranos. Si el monumento existió realmente y fue construido en tiempos de Augusto, como se deduce de la anécdota de Quintiliano, tuvo que ser instalado necesariamente en un espacio público, en el foro que estaba en uso en aquel momento, situado en la parte baja de Tarragona. Dado que no era un altar propiamente dicho, puesto que sobre él no se realizaban sacrificios, sino que se trataba más de un pedestal honorífico o conmemorativo de un hecho que no podemos precisar, no había razón alguna para que estuviera asociado a un templo y, menos aun, a un templo de culto provincial a Augusto, como sugiere R. Étienne". ${ }^{27}$

Por último, recientemente J. Beltrán describe así el reverso de la moneda: "El altar representado remite a modelos clásicos en su forma y decoración, y presenta pilastras en las esquinas del cuerpo, coronadas con pulvinos, situados sobre un ábaco cua-

\footnotetext{
23 Ruiz de Arbulo 2009, 169.

24 Ruiz de Arbulo 2009, 170, n. 23.

25 RODÁ 2007, 744.

26 CASTillo Ramírez 2008, 626.

27 ÉTIENNE 1958, 629.
} 
drangular ornamentado con zarcillos de acanto, símbolo del Saeculum Aureum. En el frente se disponen dos bucráneos de los que cuelga una guirnalda ¿de laurel?, lo que remite a los esquemas del Ara Pacis. Finalmente, en la comba de la guirnalda asoma un escudo circular, con umbo, sobre una lanza; más que a la concesión del clipeus virtutis otorgada por el Senado en el año 27 a.C., debe rememorar su virtus militar, e incluso es posible que la representación de la caetra hispánica aluda en concreto a la victoria de Augusto en las Guerras Cántabras. El altar debió situarse en el entorno del foro colonial o "foro bajo" de Tarraco, aunque se desconoce el contexto exacto. Se asocia en el anverso a un motivo frecuente en monedas de culto imperial: la cabeza del Diuus Augustus con corona radiada, en este caso de gran calidad estética, que se adecua al modelo idealizado de su retrato elaborado en vida". ${ }^{28}$

A mi juicio lo que Quintiliano trata de poner de manifiesto en su anécdota es el rechazo de Augusto a considerar este tipo de fenómenos inusuales o extraños, en este caso que una palma brote directamente de la piedra, como un prodigio, dentro por tanto de una categoría religiosa; trataría así de subrayar el desprecio, podríamos decir, a la idea del prodigio que quizá apuntaba a su divinización. Pero nada más alejado de la realidad. Creo que Suetonio está en lo cierto cuando afirma que Augusto tenía fe ciega en ciertos auspicia y omina (92.1: Auspicia et omina quaedam pro certissimis observabat) pero que también los prodigios le impresionaban mucho (sed et ostentis praecipue movebatur) y pone como ejemplo que en una ocasión brotó una palmera en los intersticios de las piedras delante de su casa; Augusto la hizo trasplantar al patio interior junto a los dioses Penates y procuró por todos los medios que arraigara (92.3: Enatam inter iuncturas lapidum ante domum suam palmam in compluvium deorum Penatium transtulit, utque coalesceret magno opere curavit). Por las características del lugar donde irrumpe, el prodigio tenía un viejo precedente: ${ }^{29}$ en el año 169 a.C. Marcio Fígulo anunció que había nacido una palmera en el impluvio de su casa pero el Senado no lo consideró como tal por haber tenido lugar en un espacio privado:

Duo non suscepta prodigia sunt, alterum, quod in privato loco factum esset,-—palmam enatam [in] inpluvio suo T. Marcius Figulus nuntiabat -, alterum, quod in loco peregrino...

(Liv. 43, 13, 4-5)

A finales de la República la interpretación de los prodigios había sufrido notables transformaciones: asistimos a la desaparición de los prodigios públicos y la multiplicación de aquellos con un claro significado personal. ${ }^{30}$ Recuérdese el rayo que cayó

28 BELTRÁN Fortes 2012.

29 Entre los honores recibidos por Augusto en el año 27 a.C. -junto a la corona civica y el clipeus virtutisfiguran dos arbustos de laurel, para ser colocados en las jambas de la casa de Augusto, según se nos dice en las Res Gestae 34, que pudieron sustituir a la palmera que brotó ante domum suam y fue luego trasplantada. El prodigio es registrado también por Obsecuente: "En Roma, en el templo de Fortuna, muchas personas vieron una culebra con cresta; nació una palmera del suelo y durante el día llovió sangre” (Obs., 69).

30 Chalupa 2012. Para el autor la causa de la desaparición de los prodigios públicos y su expiación en época de Augusto es que "they were so closely connected with the values of Roman political and religious elites and played such an important role in the process of building Roman national identity that they lost their 
cerca de su casa y que obligó a Octaviano a transformarlo en templo a Apolo. ${ }^{31}$ El sentido tanto del rayo como del elemento arbóreo es advertir la sacralidad del lugar: "pierres sacrées certes puisque le seuil de la demeure du gran pontife Auguste fils du divin César est l'equivalent de l'entrée d'un temple, et qu'un autel sert aux sacrifices", escribe Vigourt. ${ }^{32}$ Existe aún una posible conexión más entre el joven Octaviano y los árboles: en el año 38 a.C., dos años antes de la consagración del templo de Apolo en el Palatino, cuatro palmeras brotaron cerca del santuario de la Magna Mater y en el Foro, calmando así el espíritu temeroso de los romanos, angustiados a su vez por los últimos prodigios (D.C., 48.43.4). Dos estudiosos coinciden al creer que Dión lo resalta intencionadamente a la luz de la boda de Octaviano con Livia en aquel mismo año. ${ }^{33}$

Es difícil conocer el sentido o la interpretación precisa -evidentemente favorableque se dio del prodigio del altar de Tarraco. Pero sabemos que durante la guerra de Roma contra Perseo (168 a.C.), nació una palmera sobre el altar de Júpiter capitolino que según dice Plinio, fue anuncio de victoria y triunfos (NH XVII 244: Nec non et Romae in Capitolio in ara Iovis bello Persei enata palma victoriam triumphosque portendit). Eso, unido a la presencia de armas en el escudo del altar de Tarraco, hace pensar en la interpretación de un anuncio de victoria quizá en el contexto de las guerras cántabras.

Tanto la palma del altar de Tarraco como la de la casa de Augusto en el Palatino -y antes la de Trales- brotan directamente de la piedra. Filipo de Tesalónica (s. I d.C.) dedicó un epigrama a un laurel que brotó en un altar de Augusto haciendo hincapié en que nacía directamente de la roca:

"Dafne, la que antaño rechazó a Febo, hace brotar ahora sus ramas de oscuras hojas del altar del César, y en vez de aquel dios ha encontrado a un dios mejor, pues la que la desdeñó hijo de Leto desea ahora al enéada Zeus. No hunde sus raíces en la madre tierra, sino en roca: ni la piedra puede no ser fértil en honor del César"

$$
(A P ., 418=\mathrm{IX}, 307)
$$

En opinión de esta estudiosa francesa el autor, pese a mencionar un laurel, se refiere al mismo prodigio que el del Palatino dado que la equivalencia simbólica entre las dos plantas "es manifiesta". Se apoya Vigourt para identificar ambos episodios en un viejo estudio de H. Danthine ${ }^{34}$ quien "a mis en evidence que le palmier était l'arbre

rationale after the establishment of the principate, since from that time these values were invested into and this role played by Roman emperors and their families".

31 Suet., Aug. 29.4; D.C., 49.15.5. Siguiendo quizá lo sucedido a Augusto, la aparición de ostenta arboraria en la casa natal del emperador no será infrecuente en el Imperio. Además de lo sucedido en casa de los antepasados de Vespasiano, cf. lo ocurrido a Alejandro Severo: nata in domo laurus iuxta persici arborem intra unum annum persici arborem vicit. Unde etiam coniectores dixerunt Persas ab eo esse vincendos (SHA, $A S$ I 3.7).

32 VIGOURT 2001,134

33 BARRET 2002, 36: "Dio reports that the midst of these dramatic occurrences Octavian and Livia married"; SANTANGElo 2013, 241: "Dio's narrative can then move on the wedding of Octavian and Livia".

34 Danthine 1937. Más recientemente: Michel - Dansac - Caubet 2013. 
de la fécondité et la prosperité, rôle conferé par Philippe de Thessalonique au laurier miraculeux de l'autel d'Auguste". ${ }^{35}$

\section{BibLIOgRAFÍA}

BARRET, A. (2002): Livia: First Lady of Imperial Rome, New Have.

BeltrÁn Fortes, J. (2012): "El origen del culto imperial en Hispania y su reflejo en las emisiones romano provinciales", [en] M. Campo (ed.), Déus i mites de l'antiguitat. L'evidència de la moneda d' Hispània (Del 16 de febrer de 2012 a l'l de gener de 2013), Barcelona, 129-132.

BerTRAND-ECANVIL, E. (1994): "Présages et propagande idéologique: à propos d'une liste concernant Octavien Auguste", MEFRA 106/2, 487-531.

Le BoheC, Y. (2010): “Le siège de Munda en 45 avant J. C.”, [en] A. Moreno Hernández (ed.), Julio César: textos, contextos y recepción. De la Roma Clásica al mundo actual, Madrid, $87-100$.

Blanco Freijeiro, A. (1983): "La Munda del coronel Stoffel", Anexo a Ategua, Noticiario Arqueológico Hispánico 15, 130-132.

Burnett, A. (ed.) (1992): Roman Provincial Coinage. I. From the death of Caesar to the death of Vitellius (44BC-AD69), London.

CANFora, L. (2007): Julio César: un dictador democrático, Barcelona.

Castillo Ramírez, E. (2008): Propaganda política y culto imperial en Hispania (de Augusto a Antonino Pio): reflejos urbanisticos (Tesis doctoral. Universidad Complutense de Madrid).

Chalupa, A. (2012): "The Religio-Political change in the Reign of Augustus: Disappearance of Public Prodigies", Graeco-Latina Brunensia 17/2, 57-67.

Claesen, M. (1938): "Le palmier, symbole d'Apollon", Bulletin de l'Institut Historique Belge de Rome 19, 83-102.

Curbera, J. B. - Galaz, M. (1995): "Platanus Caesariana", Habis 26, 153-158.

Curchin, L. A. (2002): "Octavius in Spain (45 B.C.)”, [en] L. Hernández Guerra - L. Sagredo San Eustaquio - J. M. Solana Sáinz (coords.), Actas del I Congreso Internacional de Historia Antigua «La Peninsula Ibérica hace 2000 años». Valladolid, 23-25 de noviembre 2000, Valladolid, 153-157.

Danthine, H. (1937): Le Palmier-dattier et les arbres sacrés dans l'iconographie de l'Asie Occidental Ancienne, Paris.

Deonna, W. (1951): "L'ex-voto de Cypsélos à Delphes : le symbolisme du palmier et des grenouilles", $R H R 140,1,5-58$.

DurÁn Recio, V. - Ferreiro LóPez, M. (1984): “Acerca del lugar donde se dio la batalla de Munda", Habis 15, 229-235.

ÉtIENne, R. (1958): Le culte imperial dans la Peninsule Iberique d'Auguste à Diocletien, Paris.

35 Vigourt 2001, 134. Cf. Guillaume-Coirier 1992, 359 y 371 donde define el laurel como "la plante de tous les pouvoirs". Cf. también CLAESEN 1938. Sobre la palmera como símbolo apolíneo, cf. Le Roy 1973. 
FISHWICK, D. (1982): "The altar of Augustus and the municipal cult of Tarraco", MM 23, 222-233.

Flory, V. M. B. (1989): “Octavian and the omen of the Gallina Alba”, CJ 84, 343-356.

GArcía Ruiz, J. M. (2011): "Mineralogía y la batalla de Munda”, Macla. Revista de la sociedad española de mineralogía, 15, 95.

Gowers, E. (2011): "Trees and Family Trees in the Aeneid”, Classical Antiquity 30/1, 87-118.

Guillaume-CoIrIER, G. (1992): “Arbres et herbes. Croyances et usages rattachés aux origines de Rome", MEFRA 104, 333-371.

Le Bohec, Y. (2010): “Le siège de Munda en 45 avant J.C.”, [en] A. Moreno Hernández (ed.), Julio César: textos, contextos y recepción. De la Roma Clásica al mundo actual, Madrid, 87-100.

LE Roy, Chr. (1973): “La naissance d'Apollon et les palmiers déliens”, BCH Suppl. 1, 263286.

Marks, R. (2010): “Julius Caesar in Domitianic Poetry”, [en] N. Kramer - Chr. Reitz (eds.), Tradition und Erneuerung: Mediale Strategien in der Zeit der Flavier, Berlin, 13-39.

Melchor Gil, E. - Mellado Rodríguez, J. - Rodríguez Neila, J. F. (eds) (2005): Julio César y Corduba: tiempo y espacio en la campaña de Munda (49-45 a.C.), Córdoba.

Meulder, M. (2006): “Le platane de Jules César (Martial, “Épigrammes”, IX, 61)”, Evphrosyne 34, 313-324.

Michel-Dansac, F. - Caubet, A. (2013): “L'iconographie et le symbolisme du palmier dattier dans l'Antiquité (Proche-Orient, Égypte, Méditerranée orientale)", Revue d'ethnoécologie 4, 1-14.

MONTERO, S.

(2005): "Los árboles en los libros etruscos de adivinación", [en] R. Olmos - P. Cabrera - S. Montero (eds.), Paraíso cerrado, jardín abierto. El reino vegetal en el imaginario religioso del Mediterráneo, Madrid, 171-188.

(2006): Augusto y las aves. Las aves en la Roma del Principado: prodigio, exhibición y consumo, (=Colección Instrumenta 22), Barcelona.

(2014): "I sodales Titii: tradizione e innovazione", [en] G. Urso (ed.), Sacerdos. Figure del sacro nella società romana (Atti del convegno internazionale Cividale del Friuli, 26-28 settembre 2012), Pisa, 191-210.

Perea YéBenes, S. (2005): "La batalla de Munda, César, y el primer viaje de Octaviano a Hispania, según el testimonio de Nicolás de Damasco", Gerión 23, 2, 7-18.

RoDÁ, I. (2007): "Documentos e imágenes de culto imperial en la Tarraconense septentrional”, [en] T. Nogales - J. González (eds.), Culto imperial: política y poder, Roma, 741761.

Ruiz de Arbulo, J. (2009): "El altar y el templo de Augusto en la colonia Tarraco. Estado de la cuestión", [en] J. M. Noguera Celdrán (ed.), Fora Hispaniae. Paisaje urbano, arquitectura, programas decorativos y culto imperial en los foros de las ciudades hispanoromanas (Monografias del Museo Arqueológico de Murcia), Murcia, 155-189.

Santangelo, F. (2013): Divination, Prediction and the End of the Roman Republic, Cambridge-New York.

Sourvinou-Inwood, C. (1985): “Altars with palm trees, palm trees and parthenoi”, BICS 32, 1985, 125-146. 
Syme, R. (1959): "Livy and Augustus", HSClPh 64, 27-87.

Thulin, C. O. (1968): Die Etruskiche Disciplin. Teil I-III, Darmstadt (=1905-1909).

Vigourt, A. (2001): Les présages impériaux d'Auguste à Domitien (Coll. de l'Université March Bloch Strasbourg), Paris.

VILlalonga, L. (1977): "La amonedación de Tárraco y su aspecto petrológico", Quaderni Ticinesi di numismatica e antichità classiche 7, 139-157.

WeINSTOcK, S. (1971): Divus Iulius, Oxford. 